\title{
Status of Wind-Diesel Applications in Arctic Climates
}

Conference Paper NREL/CP-500-42401

December 2007

\section{Preprint}

I. Baring-Gould and D. Corbus

Presented at The Arctic Energy Summit Technology Conference Anchorage, Alaska

October 15-18, 2007

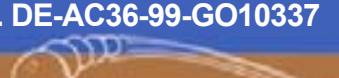




\section{NOTICE}

The submitted manuscript has been offered by an employee of the Midwest Research Institute (MRI), a contractor of the US Government under Contract No. DE-AC36-99G010337. Accordingly, the US Government and MRI retain a nonexclusive royalty-free license to publish or reproduce the published form of this contribution, or allow others to do so, for US Government purposes.

This report was prepared as an account of work sponsored by an agency of the United States government. Neither the United States government nor any agency thereof, nor any of their employees, makes any warranty, express or implied, or assumes any legal liability or responsibility for the accuracy, completeness, or usefulness of any information, apparatus, product, or process disclosed, or represents that its use would not infringe privately owned rights. Reference herein to any specific commercial product, process, or service by trade name, trademark, manufacturer, or otherwise does not necessarily constitute or imply its endorsement, recommendation, or favoring by the United States government or any agency thereof. The views and opinions of authors expressed herein do not necessarily state or reflect those of the United States government or any agency thereof.

Available electronically at http://www.osti.gov/bridge

Available for a processing fee to U.S. Department of Energy and its contractors, in paper, from:

U.S. Department of Energy

Office of Scientific and Technical Information

P.O. Box 62

Oak Ridge, TN 37831-0062

phone: 865.576 .8401

fax: 865.576 .5728

email: mailto:reports@adonis.osti.gov

Available for sale to the public, in paper, from:

U.S. Department of Commerce

National Technical Information Service

5285 Port Royal Road

Springfield, VA 22161

phone: 800.553 .6847

fax: 703.605.6900

email: orders@ntis.fedworld.gov

online ordering: http://www.ntis.gov/ordering.htm 


\section{Abstract}

The rising cost of diesel fuel and the environmental regulation for its transportation, use, and storage, combined with the clear impacts of increased arctic temperatures, is driving remote communities to examine alternative methods of providing power. Over the past few years, wind energy has been increasingly used to reduce diesel fuel consumption, providing economic, environmental, and security benefits to the energy supply of communities from Alaska to Antarctica.

This summary paper describes the current state of wind-diesel systems, reviews the operation of winddiesel plants in cold climates, discusses current research activities pertaining to these systems, and addresses their technical and commercial challenges. System architectures, dispatch strategies, and operating experience from a variety of wind-diesel systems in Alaska will be reviewed. Specific focus will also be given to the control of power systems with large amounts of wind generation and the complexities of replacing diesel engine waste heat with excess wind energy, a key factor in assessing power plants for retrofit. A brief overview of steps for assessing the viability of retrofitting diesel power systems with wind technologies will also be provided.

Because of the large number of isolated diesel minigrids, the market for adding wind to these systems is substantial, specifically in arctic climates and on islands that rely on diesel-only power generation.

\section{Introduction}

The use of diesel engines to supply power to rural communities has provided light and energy services to places where previously there has only been darkness. However, the rising cost of diesel fuel and the environmental regulation for its transportation, use, and storage, combined with the clear impacts of increased arctic temperatures, is driving remote communities to look at alternative methods to supplement this power source. Over the past few years, wind energy has been increasingly used to reduce diesel fuel consumption, providing economic, environmental, and security benefits to the energy supply of communities from Alaska to Antarctica.

This is a very exciting time for this industry. Research into systems continues as researchers receive feedback from operators and plant managers about how the systems are working. This paper describes the current state of wind-diesel technology and applications, the current research activities, and the remaining technical and commercial challenges. System architectures, dispatch strategies, and operating experience from a variety of wind-diesel systems in arctic environments are reviewed.

Because of the large number of isolated diesel minigrids in both the developed and developing world, the market for retrofitting these systems is substantial. Because this market represents an international opportunity, a community of interest has formed and is committed to sharing the technical and operating experience to expand the recent commercial successes.

\section{The World of Off-Grid Electrification}

Wind-diesel power systems can be more accurately described by the title "hybrid power system." A hybrid power system can incorporate different components, including production, storage, power conditioning, and system control to supply power to an isolated load [1].

The classic hybrid system incorporates renewable technology, fossil fuel engine generator(s), a battery bank, and a power converter. In most cases, this system is based on a two-bus system: a DC bus for the battery bank and an AC bus for the engine generator and distribution. The renewable technology may be 
attached to either the AC or DC bus, depending on the system size and configuration. These systems usually supply AC power, although some loads may be tapped off the DC bus bar. This power system configuration is used for small communities and can range in size from a few kilowatt-hours $(\mathrm{kWh}) /$ day to many megawatt-hours (MWh)/day, with no firm boundary.

This general configuration can have a great deal of internal variability, depending on the system size. Smaller systems will likely use large battery banks, providing up to a few days of storage to cover the average load, and will use smaller renewable generation devices connected to the DC bus. These systems focus around the DC bus bar, with the production of $\mathrm{AC}$ power coming from a power converter or diesel engines (Figure 1). Larger systems focus on the AC-bus bar, with all renewable technology designed to be connected to the AC distribution network. In larger systems, any storage, if used at all, is generally small and mainly used to cover fluctuations in power production. Larger systems usually contain more and larger equipment that allows for an economy of scale, and thus lower power costs

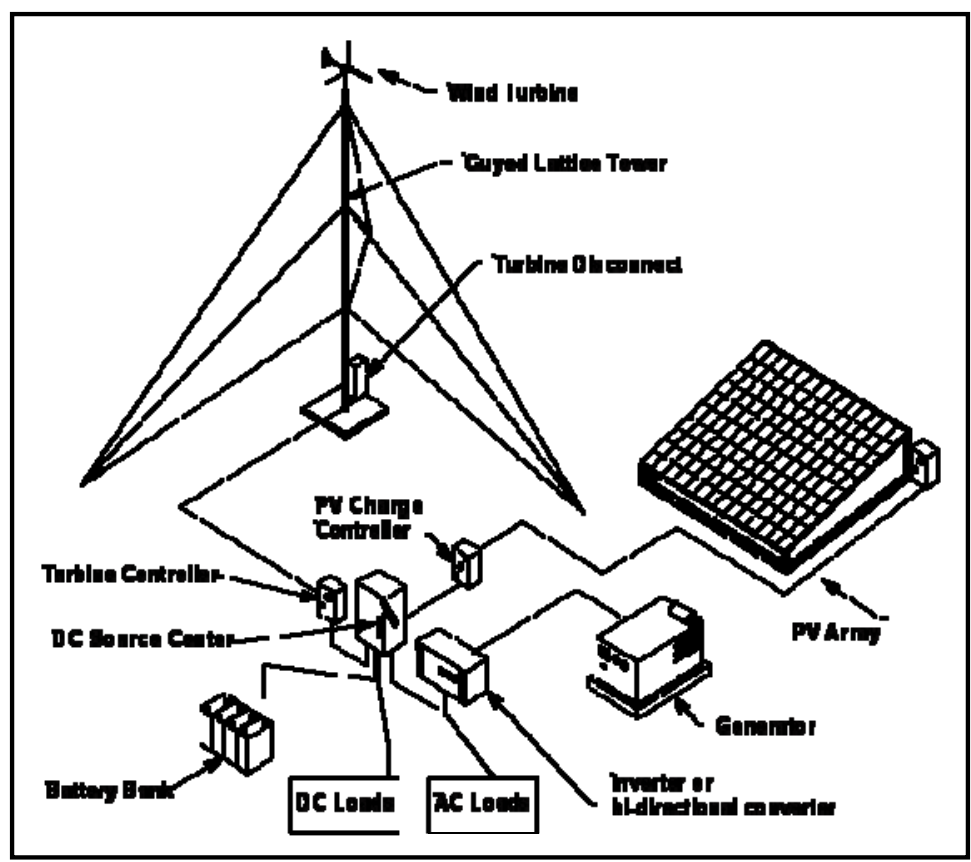

Figure 1: Basic DC-based hybrid power system to meet small isolated energy needs (Figure 2).

In systems that focus around the DC bus, the battery bank acts as a large power dampener, smoothing out any short- or long-term fluctuations in the power flow. In many ways, it regulates itself based on a few specific parameters, such as voltage. This is not the case with equipment connected to the AC grid, which is much less forgiving. The key issue is the balancing of power and voltage regulation on a sub-cycle time scale. This is largely done with the use of synchronous condensers, dispatchable load banks, short-term storage, power electronics, and advanced control systems that carefully monitor the operating conditions of each component to ensure that the resulting power has a consistent frequency and voltage.

\section{Topography of Power Systems Combining Wind and Diesel}

Wind-diesel power systems can vary from simple designs in which wind turbines are connected directly to the diesel grid with a minimum of additional features, to more complex systems in which advanced controls and components are required [1, 2, 3, 4,5]. Two overlapping concepts depict the system design and required components: the amount of energy that is expected from the renewable sources (system penetration) and the methods that will be used to control the power system, depending on the level of renewable contribution. In cold climates, the use of waste energy from the diesel engines also plays a critical role in determining power system design. 


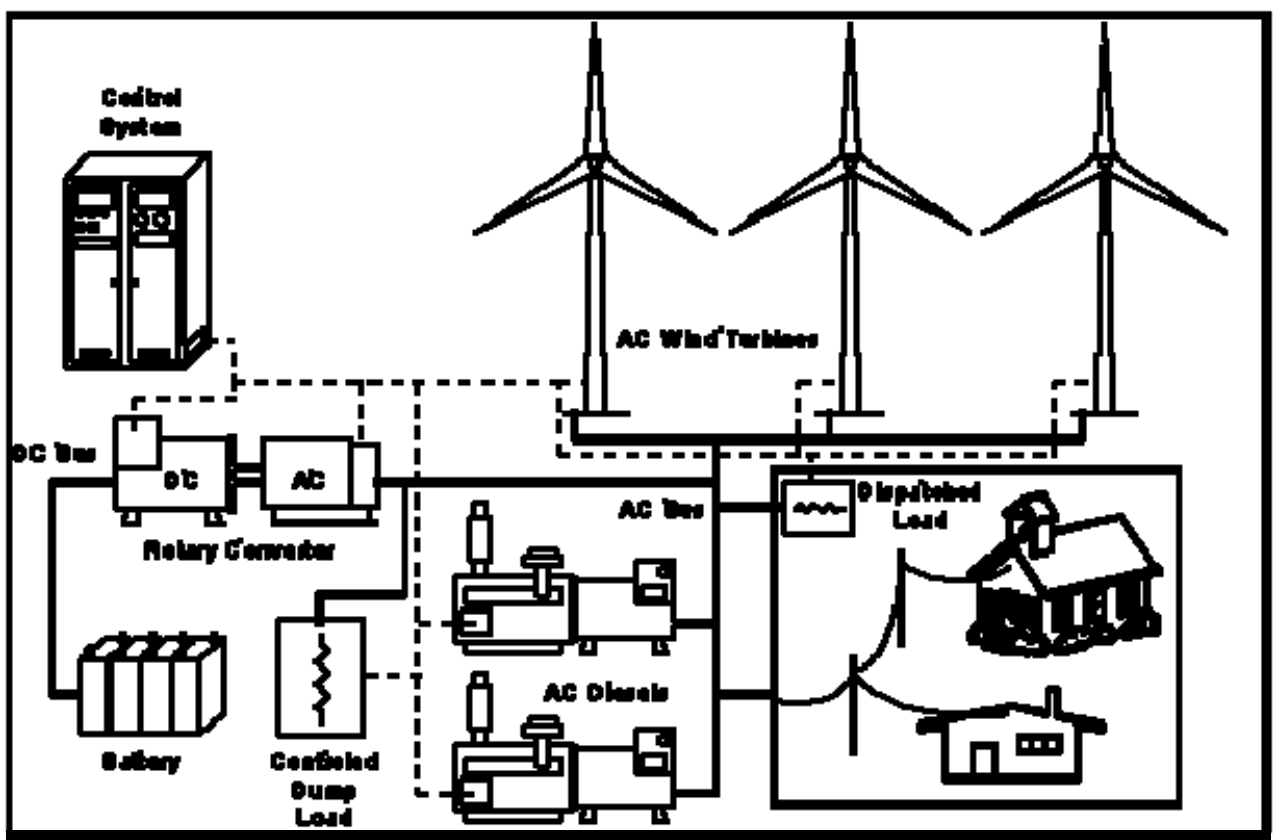

Figure 2: Schematic of a wind-diesel power system using battery storage and other control devices to provide power to a community using wind and diesel technology

\section{Renewable Penetration}

In almost all cases, the systems control requirements increase with increasing reliance on energy from wind turbines. Steve Drouilhet, an engineer formerly with the National Renewable Energy Laboratory and currently with the private company Sustainable Automation, developed the following classification and definitions of system penetration that help to characterize the levels of system control complexity:

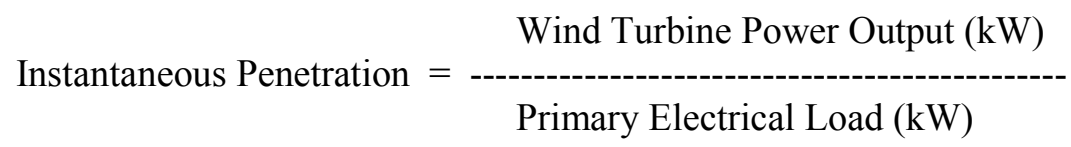

And

Average Penetration $=\frac{\text { Wind Turbine Energy Output }(\mathrm{kWh})}{\mathrm{Primary} \text { Electrical Load }(\mathrm{kWh})}$

The difference in these equations is the units. Instantaneous penetration is in terms of power; thus, it is the ratio of how much power is produced by the renewable resources at any specific instant. The average penetration is in terms of energy; it includes a time domain and is thus measured over days, months, or even years.

Instantaneous penetration relates to the complexity of the power system and the required level of control that will be needed to maintain acceptable power quality. Power systems with low levels of wind energy require limited additional control because the wind energy generally acts as a negative load. System control is provided by devices integrated into diesel generator hardware. As instantaneous penetrations increase, more care is required because the variation in wind turbine output, driven by the variation of the wind resource, may overwhelm the capabilities of standard diesel control hardware. At very high levels of 
instantaneous penetration, where wind production is on par or even exceeds the system energy requirements, additional control must be put in place to maximize system performance and stability (including, in some cases, limited energy storage).

Average penetration is more the domain of the economist or plant planner. Averaged over longer periods of time, it provides a record of the total amount of system energy coming from wind technology. This allows an estimate of fuel savings and fuel storage needs, general system operation characteristics, and potential long-term monetary impact.

Drouilhet also proposed a three-level classification system based on system penetration that separates systems along power and system control needs (Table 1). The instantiations and average penetration levels provided in the table should be considered approximate and will depend greatly on the age of the diesel generator and associated controls. The potential need for additional energy, typically space or water heating in polar climates, that is typically generated through other means, such as using the jacket and exhaust heat from the diesel plant, complicates the matter. The following section provides more specific information on the different levels of system penetration.

LOW-PENETRATION SYSTEMS: Low-penetration systems are those in which the wind energy contribution to the power system is rather limited, requiring no special arrangements or control requirements. In low-penetration systems, instantaneous penetrations are likely to be below $50 \%$, and in many ways the energy generated by the wind turbines is seen as a negative load on the diesel plant. The control technology required at this level

Table 1: Penetration Class of Wind/Diesel Systems (Proposed by Steve Drouilhet)

of generation is trivial, especially given the control, flexibility, and speed of modern diesel and wind systems. In systems incorporating older diesel engines, especially those using lowspeed diesel technology, the upper limit of what is considered low penetration may shift lower. Generally speaking, in lowpenetration systems, no form of automated

\begin{tabular}{|c|c|c|c|}
\hline \multirow{2}{*}{$\begin{array}{l}\text { Penetration } \\
\text { Class }\end{array}$} & \multirow[b]{2}{*}{ Operating Characteristics } & \multicolumn{2}{|c|}{ Penetration } \\
\hline & & $\begin{array}{c}\text { Peak } \\
\text { Instantaneous }\end{array}$ & $\begin{array}{l}\text { Annual } \\
\text { Average }\end{array}$ \\
\hline Low & $\begin{array}{l}\text { - } \quad \text { Diesel(s) run full-time } \\
\text { - } \quad \text { Aind power reduces net load on diesel } \\
\text { - No supervisory control system }\end{array}$ & $<50 \%$ & $<20 \%$ \\
\hline Medium & $\begin{array}{l}\text { Diesel(s) run full-time } \\
\text { At high wind power levels, secondary } \\
\text { loads dispatched to ensure sufficient } \\
\text { diesel loading or wind generation are } \\
\text { curtailed } \\
\text { Requires relatively simple control } \\
\text { system }\end{array}$ & $50 \%-100 \%$ & $\begin{array}{l}20 \%- \\
50 \%\end{array}$ \\
\hline High & $\begin{array}{l}\text { Diesel(s) may be shut down during high } \\
\text { wind availability } \\
\text { - } \quad \begin{array}{l}\text { Auxiliary components required to } \\
\text { regulate voltage and frequency }\end{array} \\
\text { - } \quad \text { Requires sophisticated control system }\end{array}$ & $100 \%-400 \%$ & $\begin{array}{l}50 \%- \\
150 \%\end{array}$ \\
\hline
\end{tabular}
control is required - the wind turbines act under their commercial controllers and an operator monitors all system functions. Because the diesel engines are designed to allow for rapid fluctuations in power requirements from the load, the addition of wind has very limited impact, if any, on the ability of the diesel control to provide the remaining difference. In some instances, individual wind turbines may be 
shut off to reduce the amount of energy from wind, but this occurs relatively rarely in well-designed systems. Issues of spinning reserve, a term used to represent the availability of instantaneous system capacity to cover rapid changes in system load or energy production, are addressed by the allowable capacity of the diesel engines, which in many cases can run at $125 \%$ rated power for short periods of time with no adverse impact on the diesel or generator.

Many low-penetration systems have been installed worldwide. These vary from small to relatively large isolated grids, such as those found on several Greek islands. The power system that has operated in Kotzebue, Alaska (a coastal community of more than 3000 people in northern Alaska) for almost 10 years is generally classified as a low-penetration power system. [6]

MEDIUM-PENETRATION SYSTEMS: Systems with larger ratios of renewable energy contribution in which some level of power system control is required fall into this category. In order to maintain minimum load levels on the diesel generators in multiple diesel plants when a larger portion of the energy is produced by a wind source, some diesels must be shut off or have production switched to a smaller unit. This lower level of diesel generation makes it harder for the operating diesel units to tightly regulate system voltage and maintain an adequate power balance, requiring the addition of additional system controls and system stability devices. Several options exist to ensure that the high-power-quality requirements of the power system are maintained, even with half of the energy provided by renewable sources. Some of the options include:

- Potential power reduction capabilities of the wind turbines

- Including secondary loads, thus increasing the overall system load and ensuring that no more than a specified amount of energy will be generated by the wind

- Using controlled dump loads to assist in clipping the peaks off wind variability, thus assisting in the control of frequency

- Installing capacitor banks to correct power factor

- Using advanced power electronics to allow real-time power specification.

Maintaining the proper level of spinning reserve in medium-penetration power systems requires experience in regard to power variability and system control, but it is not considered technically complex. Such spinning reserve questions should be handled on a case-by-case basis but can be partially solved by using options including advanced diesel controls, the installation of a modern diesel engine with fast-start and low-loading capabilities, controlled load shedding or reduction, power forecasting, and proper system controls. Combined with the use of variable-speed or advanced power control available on many modern wind turbines, the power quality requirements of medium-penetration systems are still quite simple.

However, even with the implementation of advanced power conditioning or power smoothing technology, diesel engines have a minimum load rating under which manufactures state that the diesels should not be operated. Not only does operating under these levels, typically $40 \%$ to $50 \%$ of the engine's rated power, reduce the diesel governor's ability to control frequency and voltage, but they also force the engine to run at cooler temperatures, thus causing increased engine carbon build up, wet stacking, and higher maintenance requirements. This minimum diesel-loading requirement acts as a glass ceiling, limiting the benefit of incorporating increasing amounts of wind into a diesel power system. To allow higher penetrations of wind into small diesel systems, several companies have introduced diesel engines that can operate at very low load, generally down below $10 \%$ rated power [7]. These low-load diesels maintain their ability to control voltage and frequency at low power levels but also act as spinning reserve because of an ability to respond quickly to step changes in load. 
However, medium-penetration systems are more complex, and almost invariably increased complexity results in increased cost. These costs must be compared against reduced plant diesel consumption, reduced diesel engine operation, and reduced needs for fuel storage, all leading to reduced environmental impact and air emissions.

The ability to provide high power quality in medium-penetration power systems has been demonstrated for years in a number of important locations. The most notable examples are the military diesel plants on San Clemente Island [8] and Ascension Island [9] and the power system in Toksook Bay and Kasigluk, Alaska [5]. Several systems have also been installed using low-load diesel technology, including power systems at Coral Bay and Denham, Australia. [10] All of these systems have experienced power penetration at or above general guidelines set for medium-penetration systems (shown in Table 1).

HIGH-PENETRATION SYSTEMS: As instantaneous penetrations of renewable energy rises, eventually more energy (and potentially a lot more energy) can be created than is needed by the general community load. With wind providing a large amount of the load, the ability of the diesel engines to control frequency and voltage is significantly reduced. Additionally, unless there is a great need for additional energy - thermal or electrical - then it makes financial sense to shut off many (and preferably all) of the diesel engines when the whole load can be supplied by renewable sources, the basic hallmark of a high penetration wind-diesel system. The operational concept behind these systems is that additional equipment is installed that can insure power system stability and power quality when the diesel engines, the device that typically controls these parameters, is shut off. In this case, any instantaneous power production over the required electrical load, an instantaneous penetration over $100 \%$, is supplied to a variety of controllable secondary loads. In these systems, synchronous condensers, load banks, dispatchable loads, power converters, advanced system controls, and possibly storage in the form of batteries or flywheel systems are used to ensure power quality and system integrity.

Spinning reserve is created through the use of short-term storage or the maintenance of a consistent oversupply of renewable energy. This reserve is designed to either ride out short lulls in wind power or allow a diesel to be started to assume the load if the wind is not adequate.

Although high-penetration wind diesel systems are being demonstrated commercially, they are not yet considered a mature technology and have not been demonstrated on systems larger than approximately $300-\mathrm{kW}$ average load. High-penetration wind-diesel power stations also require a much higher level of system integration, technology complexity, and advanced control, increasing the project cost, but they reduce fuel consumption and diesel engine operation significantly.

Until recently it was assumed that high-penetration wind-diesel systems without storage were primarily theoretical, possible over short time periods in test-stand-based power systems but not really feasible in community-based applications. This is no longer the case. Commercially operating short-term and no storage systems have been installed in recent years, demonstrating that either choice is viable.

In systems incorporating storage, the storage is used to cover short-term fluctuations in renewable power. The premise of this system design is that when the renewable-based generators supply more power than is needed by the load, the engine generators can be shut down. During lulls in the renewable power generation, discharging the battery bank or other storage device supplies any needed power. If the lulls are prolonged or the storage becomes discharged, an engine generator is started and takes over supplying the load. Studies have indicated that most lulls in power from the wind are of limited duration, and using storage to cover these short time periods can lead to significant reductions in the consumption of fuel, generator operational hours, and reduced generator starts $[11,12]$. 
In recent years, two types of storage have been successfully demonstrated in operational rural power systems: battery storage and flywheels. Battery storage has clearly been the most commonly used, taking advantage of the long operational history of battery storage technologies. Systems incorporating nickel cadmium (NiCad) batteries and rotary power converters such as those incorporated into the power system for Wales, Alaska [13] and the vanadium-based flow battery used at Kind Island, Australia [14,15] indicate that battery technology can be used to smooth out wind power fluctuations, both in small and large power systems. Although relatively proven, depending on the type, batteries also introduce a host of problems. They are large and unwieldy, they use exotic hazardous liquids, and in many cases they have a limited life and require consistent maintenance.

Although researched extensively in the 1980s, flywheel technology is becoming more common as a method to provide short-term power storage. Although flywheels don't provide the longer-term storage of up to several minutes provided by batteries, in power systems such as Coral Bay and Flores Island, flywheels are being used to provide short-term power storage $[10,16]$. One of the key aspects of flywheel technology is the units' ability to supply lower levels of power for longer periods of time, up to several minutes, or short bursts of high power for very short periods of time. Although several products are on the market, the PowerStor ${ }^{\circledR}$ product from PowerCorp Australia that was used in the two aforementioned projects can provide power up to $1 \mathrm{MW}$ for 15 seconds or a more reasonable $150 \mathrm{~kW}$ for 100 seconds. These units are also designed in a modular fashion and can be stacked to provide higher power ratings over longer storage times. Although generally still high in cost, their smaller system footprint and long operational life make them a strong candidate for future storage applications. Finally, hydrogen storage has been incorporated into remote community-based wind-diesel power systems to provide storage (although at this point it is still in the early development phase).

In large power systems, installing storage to cover shortfalls in renewable production may not be feasible, mainly due to cost. However, without the use of storage, it is very difficult to control the stability of a conventional power grid with large quantities of renewable power - thus the challenge of hybrid systems without storage. The basic premise of these systems is that the installed capacity of the renewable technology is much larger than the load. When the renewable devices are operating and producing more energy than is needed by the load by some margin, usually between $125 \%$ and $150 \%$, the dispatchable generators can be turned off. External control devices are used to maintain system stability and control. If the renewable energy dips below the specified threshold, a generator is started to insure power security, or some of the dispensable loads can be disconnected to increase the system's headroom. This type of system produces a large amount of extra energy that must be used if the project is to be economically feasible. The power system installed on the Alaskan Island of St. Paul to supply the airport and co-located industrial complex is an example.

Unlike flywheels and standard batteries, hydrogen and technologies such as the vanadium-based flow batteries can provide long-term storage for wind-diesel power systems. Although longer-term storage has been applied in many smaller hybrid applications, their use in larger hybrid wind-diesel systems is relatively new. As has been found in smaller applications, longer-term storage allows the displacement of more fossil fuels by using renewable-generated energy when the renewable resource is not actually available. However, although the cost of the renewable-generated energy might be relatively low, the efficiency and cost of the storage medium is in effect competing against the incremental cost of energy from a diesel generator, which is also generally low for large power plants with defined fuel supply chains. The current cost of fuel has largely limited the implementation of wind systems with large storage components to technical demonstration projects such as the power system on King Island [14,15] or the first large-scale remote wind-hydrogen development where two Enercon E-44 900-kW wind turbines supply power to 10 homes on the remote Norwegian Island of Utsira [17]. In locations with very high fuel costs, or if standard fuel costs rise sharply, longer-term storage may become attractive. 


\section{Demonstrated Hybrid Power Systems in Arctic Climates}

To reduce the cost of rural power generation, community vulnerability to rising diesel fuel costs, and the environmental impact of diesel fuel usage in remote communities, many organizations within the State of Alaska have implemented wind-diesel hybrid power systems. The following projects provide examples of these systems.

\section{Kotzebue, Alaska: Low-Penetration Wind-Diesel Power System}

Above the Arctic Circle, the coastal community of Kotzebue is located on a spit of land facing the Kotzebue Sound. The community of approximately 3000 individuals serves as a regional hub for this part of northwest Alaska, with a major regional airport, schools, hotels, restaurants, small industry, and a residential sector. The Kotzebue Electric Association (KEA) supplies power to the community, which has an average load of approximately $2.5 \mathrm{MW}$ and a minimum of $700 \mathrm{~kW}$. The diesel plant has an installed capacity of $11 \mathrm{MW}$. [5]

KEA initiated its wind development projects in 1997, starting with the installation of three Atlantic Orient Corporation (AOC) 15/50 50-kW-rated wind turbines on lattice towers on a location south of the main town and airstrip. Since then, the wind farm has grown to an installed capacity of $915 \mathrm{~kW}$ comprised of 17 turbines: 15 AOC 15/50 or Entegrity EW15 $(50 \mathrm{~kW})$, one remanufactured Vestas V17 $(65 \mathrm{~kW})$, and one Distributed Energy Systems Northwind 100/19 $(100 \mathrm{~kW})$. Although the annual average wind speed measured at the site is quite low (about $5.5 \mathrm{~m} / \mathrm{s}$ based on data collected at the site between 1998 and 2004), the wind turbines generated about $667,580 \mathrm{kWh}$ last year, saving an estimated 45,500 gallons of diesel fuel [19]. Specific penetration values were not obtained from this plant, but at this time only turbine curtailment is used to control at times of high wind output [20]. Data collection conducted by the DOE and the Electrical Power Research Institute on the wind farm through 2004 showed a relatively high system availability. Including wind farm downtime due to power transmission outages, each turbine was available for approximately 8000 hours per year, a 92\% turbine availability. Although more current assessments have not been published, these availability numbers have remained consistent on an annual basis [19]. This clearly demonstrates the ability for wind turbines to operate in remote communities with high turbine availability, primarily due to strong technical capabilities and dedication of the staff and management of the Kotzebue Electric Association.

\section{Toksook Bay, Alaska: Medium-Penetration Wind-Diesel Power System}

Toksook has a population of approximately 560 people and an average load just under $300 \mathrm{~kW}$. The power system is operated by the Alaska Village Electric Cooperative (AVEC) and incorporates three Northwind 100/19 100-kW wind turbines that were installed in the fall and winter of 2005/2006. The turbines are dispatched to maintain operating levels, and community heating dump loads were added to address fast overload conditions (although in recent operation very little energy has been applied to heating) [17].

Except for some initial shake-down issues, including a blade failure, the power system is operating satisfactorily, providing $22.5 \%$ of the community's load from January through August 2007 and producing almost $630,000 \mathrm{~kW}$ of wind-generated energy over the past year [18]. During some months, average wind penetration has been as high as $28 \%$, and instantaneous penetration levels have not been analyzed. The project, which was implemented as part of a complete power system upgrade, will help restrain the increased costs of electrical generation caused by rising fuel prices.

\section{Wales, Alaska: High-Penetration Wind-Diesel Power System}

This community of approximately 150 inhabitants sits on the western tip of the Seward Peninsula, looking out onto the Bering Straight about 180 miles southwest from Kotzebue and the western-most 
community on the North American mainland. The average electric load for the community is about 60 $\mathrm{kW}$, although there are also substantial heating loads for buildings and hot water.

In 1995, the Alaska Energy Authority, Kotzebue Electric Association, Alaska Village Electric Cooperative, and NREL began collaboration to implement a high-penetration wind-diesel hybrid power system in a community in northwest Alaska. The project was intended to be a technology demonstration and a pilot for commercial system replication in other rural Alaskan communities.

The Wales wind-diesel hybrid power system, which underwent final commissioning in March 2002, combines three diesel generator sets with a combined power of $411 \mathrm{~kW}$; two $65-\mathrm{kW}$ AOC 15/50 wind turbines; and a 130-Ah battery bank comprised of SAFT nickel cadmium batteries, an NREL-built rotary power converter, and various control components. The primary purpose of the system was to meet the village electric demand with high-quality power while minimizing diesel fuel consumption and diesel engine run time. The system also directs excess wind power to several thermal loads in the village, thereby saving heating fuel. The plant control logic was developed so that if any particularly piece of equipment was not operational, then the power system would revert to a mode that allowed the most advantageous operation. For example, if the rotary converter was not operational to provide energy storage or high-penetration power control, the system controller would dispatch the turbines to operate as a medium-penetration system. If all else failed, the diesels would provide primary power [13].

Unfortunately, limited data have been taken on system operation in all the different modes of operation, but one 18-day test period during August 2002 reported wind-only power system operation for $20 \%$ of the system operating time. August also represents one of the lower-wind-speed months in Wales. During this same test period, the wind turbines supplied $41 \%$ of the consumer load, while the diesel engine supplied the rest. The wind turbines also supplied almost $10,000 \mathrm{kWh}$ of electric energy to the system heating loads, saving an estimated 450 liters of heating fuel. It was expected that the two wind turbines would provide an average penetration of approximately $70 \%$, saving $45 \%$ of expected fuel consumption and reducing the operational time of the diesel engines by $25 \%$.

Unlike the Kotzebue projectt, which has seen the slow expansion of the wind facility, and Tooksok Bay, which was completed as part of a complete system upgrade, this project was developed as a retrofit of the existing diesel plant, which posed many implementation challenges [20]. Additionally, since its initial commissioning, many problems have been noted with the power system, some technically and some operationally. The complexity of the power system has resulted in numerous, and in some cases longterm, wind system outages. These have been mainly due to the long lead times required to troubleshoot and replace components, some of which can be as minor as controller modules or relays. The second major problem has been the reluctance of the system operator to allow the power system to operate in a full high-penetration mode, due primarily to a perceived or real increased instance of poor power quality, which in turn elicits negative feedback from other local community members.

Although the project has been an operational disappointment and program funding limitations have reduced the collection of plant data, the power system provided a good learning platform for the technology.

\section{St. Paul, Alaska: High-Penetration Wind-Diesel Power System}

The Tanadgusix Corporation (TDX), a native Alaskan corporation, needed a stand-alone power system for its facility on the island of St. Paul in the Bering Sea. The site is an airport and industrial complex with airline offices, equipment repair, and storage facilities. TDX wanted to reduce the overall energy costs for the camp's electrical and heating loads while maintaining reliable, utility-grade electrical service. In 1999, Northern Power Systems (now Distributed Energy Systems) installed a high-penetration, nostorage hybrid power system that maximizes the contribution of St. Paul's abundant wind resource. The 
primary components of the Saint Paul plant included a 225-kW Vestas V27 wind turbine, two 150-kW Volvo diesel engine generators, a synchronous condenser, a 27,00 liter (6,000 gallon) insulated hot water tank, and a microprocessor-based control system capable of providing fully automatic plant operation.

The primary electrical load for the facility averages about $85 \mathrm{~kW}$, but the system also supplies the primary space heating for the facility (with excess power from the generators and thermal energy from the diesel plant). Although the power system operated well over the past 7 years, a few problems have been associated with the wind turbine, most specifically a failure of the turbine generator, which had to be replaced. Although off line for several months in these early years, the project has operated quite successfully, with both of the diesel engines off for much of the high wind season [20]. In 2004, for example, the wind turbine had a $100 \%$ availability and a capacity factor of more than $40 \%$.

TDX is currently working with the City of St. Paul to interconnect two additional Vestas V27 turbines installed over the winter of 2007 to the City of St. Paul Municipal Electric Utility. This would interconnect the industrial complex power system with $725 \mathrm{~kW}$ of installed wind capacity to the city's utility electric system, driven by a $2,125-\mathrm{kW}$ diesel power station and having an average load of more than $600 \mathrm{~kW}$. With a minimum load close to $400 \mathrm{~kW}$, once interconnected the wind will be able to supply a large amount of the power for the community, and depending on the final selection of control hardware, will represent a high-penetration power system for the whole community of St. Paul $[18,21]$.

\section{Technical and Commercial Challenges}

Many challenges face the adoption of wind technologies into the arctic rural energy market, a market that is almost exclusively served by diesel-fueled generators. The dominance of fossil fuels to provide energy to remote areas is well justified based on a strong track record with many years of operational experience. However, many recent changes in arctic areas have caused public and private organizations to question the continued long-term reliance on fossil fuels alone. These changes include increasingly high and variable costs of fuel and the economic toll this places on already struggling rural communities, the impacts of climate change to native culture and site accessibility, the greater consideration for the environmental impact of fuel transport and storage, and the vastly improved quality of wind technology.

However, the incorporation of wind technologies into remote rural communities adds a host of challenges that must be considered as part of any rural energy project. Some of these items are simply symptomatic of the industry and application, while others can be largely solved by expanded research, development, and experience with operating power systems.

\section{Wind Turbine Operation in Arctic Climates}

One of the foremost challenges regarding the application of wind-diesel technologies in the arctic is the adaption of technology to arctic climates and the associated operational and maintenance issues that these added external conditions impose. Much work has been done looking at specific considerations of arctic operation, but critical elements remain elusive. On the positive side, most wind turbine manufactures have a strong understanding of turbine operation in cold climates and thus should be able to provide wind turbines that are rated to operate at extreme temperature in extreme conditions. Turbines that cannot be provided with such packages should clearly be avoided. However, even with turbines that are designed to be operated in extreme conditions, cold temperatures, extreme icing, or strong winds may make accessing the turbine for troubleshooting or repair difficult.

Icing can also play a role in the operation and accessibility of turbines, but only in places where glaze or rime icing is common. An icing event a few times a year that melts off quickly should not be a concern. Prolonged icing combined with low temperatures, however, could prevent a turbine from operating for long periods of time. The local icing regime is typically known in arctic communities, which reduces the 
need for more detailed icing assessments. Additionally, turbines installed close to the coast but at an altitude away from common in-cloud icing usually experience few issues. More research on wind turbine operation in cold climates can be found on the International Energy Agency Web site, wind energy research partnership on wind turbine operation in arctic climates at http://arcticwind.vtt.fi/ or in associated state-of-the-art and recommendations documents [22, 23].

\section{Importance of Waste Heat}

In climates with large heating loads, it is typical to extract thermal energy from the combustion cycle of the diesel plant, either through the engine cooling system or taking heat from the diesel exhaust. The inclusion of wind into a diesel plant reduces diesel operation, thus reducing the amount of thermal energy generated. If the plant is using or selling that thermal energy, the economics of generating that energy by other means, such as a diesel boiler, must be taken into account when assessing the impact of incorporating wind. This is especially the case in high-penetration wind systems in which all of the diesel engines may be shut down, eliminating all thermal heat from the diesel system plant. This is typically not a big issue because diesel boilers typically have a much higher efficiency than the thermal energy that can be removed from the generation combustion cycle, but it must be taken into consideration. Additionally, as more wind capacity is installed, increasing the plant's penetration, more energy will be generated by the wind turbines that can be used to meet thermal loads.

\section{Lack of Guidelines and Standards}

A major key to success in the development and application of any new technology is proper guidelines and standards to ensure that all market players can be held accountable for products produced and advertised. As with many new markets, new organizations are quick to step to the plate advertising the capabilities that in all likelihood are outside of their experience. In some industries this is permissible, but in the developing market for wind-diesel applications, which are generally very technically challenging, experience is the only sure indication of project success. Several research and state organizations are developing general guidelines and/or draft standards to ensure that advertised products meet a specific set of requirements, or at the very least can be designed to pass a set of specified tasks, which can then be used to test the system prior to formal hand-off. However, to ensure that improperly developed projects don't negatively impact public perception, every project must be developed by organizations with a proven track record in the development of wind and diesel technology.

\section{Lack of an Established Technology Track Record}

Although wind-diesel applications have been operating in Alaska and other arctic locations for almost 10 years, very limited documentation exists that would allow other organizations to accurately assess their operation. The only systematic data collected up to this point is from the Kotzebue wind farm (January 1999 through July 2004). This data, however, only assessed the operation of the wind farm and was not correlated to diesel plant operation or output. Additionally this analysis did not include costs for system construction, operation, and maintenance [24].

This lack of data makes it difficult to perform more definitive assessments of technology performance and costs, a critical element in the assessment of potential future projects or to document the benefits of using wind technologies. Since many of the existing plants are relatively new, even with available data, the reduced volume and its focus on the first few years of project operation will skew the results, making assessments on the long-term performance and costs for system operation and maintenance very speculative. The absence of the data makes it very easy for proponents of the technology to brush aside the desire to further develop wind-diesel applications, even if the best available analysis indicates that the projects provide positive benefits to everyone involved. Work is ongoing to better document the performance of the existing wind-diesel applications in Alaska with the hope to clearly and accurately document the true performance of these systems. 


\section{Foundation and Installation Expense}

Construction projects in rural areas, especially arctic areas, are always more difficult and more expensive than projects conducted in more temperate climates. Implementing wind technology, which typically requires developing large foundations and using cranes to raise the turbines, just adds to the expense. Permafrost conditions in Alaska, especially given the more expansive seasonal fluctuations in permafrost depth seen in certain areas, exacerbate the problems. Recent studies have shown that wind energy projects in Alaska typically cost between $\$ 2,500$ and $\$ 7,000$ per kilowatt of installed wind capacity; depending on the community's size, accessibility, and soil conditions [25]. This is generally two to three times the costs of wind turbine installations in more temperate areas. Of this, only about $30 \%$ of the costs relate to the actual turbine and tower hardware, a basic reversal of most project development costs where the turbine and tower comprise approximately $70 \%$ of the total project costs.

\section{Next Steps and Research Needs}

Wind-diesel applications can make financial sense for many Arctic locations. More than 50 have been identified in Alaska alone [25]. If fuel prices continue to increase, this number will only increase. However, this will not guarantee the further development of wind-diesel applications because several policy and technical challenges remain.

\section{Policy Challenges}

Given the level of state and federal funding for supplying energy to rural communities and research stations, primarily through diesel engines, policy plays a critical role in developing new technology paradigms. The following key policy issues should be addressed:

- Creation or streamlining of state or federal policy and funding to support the development of wind-diesel systems. For example, as with rural development in many areas, the State of Alaska will pay the complete cost for a new diesel power station and bulk fuel tank farm, even for a private power company, but it requires a local cost share to implement a wind energy project.

- State- or federal-mandated consideration of the risks and local impacts of investment in diesel power generation compared to other generation solutions. For example, since fuel is considered an operational cost, power plant managers can pass fuel-driven cost increases on to the customers. This places all risks of fuel cost volatility on the community and removes any motivation by the plant operators, or in many cases state regulators, to support lower-risk options.

- Development of regional implementation approaches to support the co-development of systems in a number of communities, resulting in economies of scale for system implementation and leading to a viable operation and maintenance infrastructure.

- Continued efforts to further education regarding wind technologies through expanded workshops, classes, and training programs.

\section{Technical Challenges}

The current high cost of rural wind and wind-diesel development clearly indicates that technology improvements are needed to ensure expanded use of wind technologies for rural electrification. The following technical issues form the heart of this list:

- Collection, analysis, and dissemination of wind-diesel power system performance and cost information

- Development of lower-cost turbine foundations and installation processes that don't require the use of cranes, many of which must be barged into rural communities and held for long periods of time

- Expanded development of packaged systems that combine all required components prior to installation in a rural community. This could be developed in combination with a more-flexible plug-and-play control architecture. 
- Expanded development of lower-cost storage technology, allowing high-penetration systems to be implemented at lower cost

- Development of standards or guidelines for wind-diesel systems and controllers, including defined commissioning procedures to ensure acceptable system operation following installation

- Availability of modern wind turbines in the appropriate size range to incorporate into wind-diesel applications.

\section{Conclusions}

There is obvious interest and motivation to add wind technology "arrows" to the "quiver" of options to provide energy services to remote communities and research installations. However, due to a lack of knowledge and documentation, in many cases the rationale for adopting wind technology to reduce the dependence on diesel fuel is rather weak. Analytic studies indicate that in locations with good wind resources, the life-cycle cost of incorporating wind is generally positive, meaning that it will save money in the long run, but the calculations are usually based on very sketchy information regarding the performance of wind-diesel systems in these environments. However, the option of waiting for another 10 years to "see how the technology matures" guarantees that in 10 years, hundreds of diesel plants will have been installed or upgraded without considering alternatives, and very little new information will have been gained. The result of this course of action could be minimal - if fuel prices drop and the world decided to tackle climate change directly, or it could be catastrophic - with fuel prices doubling as they have in the past year and the stranding of many rural communities due to environmental change. Clearly wind, or any other technology for that matter, will not replace diesel technology in providing energy to rural communities in the near term. But we must decide whether to invest the resources to ensure there are multiple arrows for this quiver. These decisions are ours to make - the true question is whether we make these decisions with an eye to the future or looking at the past.

\section{Acknowledgments}

This work was funded by the U.S. Department of Energy, Wind and Hydropower Technologies Program and the Alaska Energy Authority with support from staff of the Alaska Village Electric Cooperative, Alaska Energy Authority, and Kotzebue Electric Association.

\section{Bibliography}

[1] Lundsager, P.; Baring-Gould, E. I. (2005). Chapter 14: Isolated Systems with Wind Power. Ackermann, T., ed. Wind Power in Power Systems. New York: John Wiley \& Sons, Ltd. pp. 299329; NREL Report No. CH-500-35665.

[2] Hunter, R.; Elliot, G. Wind/diesel Systems. Cambridge, UK: Cambridge University Press, 1994.

[3] Lundsager, P.; Bindner, H. "A Simple, Robust, and Reliable Wind/Diesel Concept for Remote Power Supply.” World Renewable Energy Congress III, Reading, UK, 11-16 September 1994.

[4] Baring-Gould, E.I.; Flowers, L.; Lundsager, P.; Mott, L.; Shirazi, M.; Zimmermann, J. (2003). "World Status of Wind Diesel Applications." Proceedings of the 2003 AWEA Conference, Austin, TX. June 2003.

[5] Nelson, V.; Foster, R.; Clark, N.; Raubenheimer, D. Wind Hybrid Systems Technology Characterization, technical report, Southwest Technology Development Institute, New Mexico State University, May 2002. http://solar.nmsu.edu/publications/wind_hybrid_nrel.pdf

[6] Alaska Energy Authority, Wind Program operating wind systems in Alaska; http://www.akenergyauthority.org/programwindsystem.html

[7] PowerCorp Austrailia, Low Load Diesel - Wind/Diesel Product Description and Data Sheet. http://www.pcorp.com.au/images/pcorp-pdfs/low-load-diesel-product-\%20specification.pdf 
[8] Olsen, T.; Gulman, P. J.; McKenna, E. (2000). Wind Power Plant Evaluation Naval Auxiliary Landing Field, San Clemente Island, California; Period of Performance: 24 September 1999 - 15 December 2000. 103 pp.; NREL Report No. SR-500-27527.

[9] Idaho National Laboratory, power systems programs, http://www.inl.gov/powersystems/ascension island.shtml

[10] PowerCorp Austrailia, project descriptions for Coral Bay and Denham (low-load diesel) and Coral Bay and Flores Island (flywheel), http://www.pcorp.com.au/index.php?option=com content\&task=view\&id=83\&Itemid=132

[11] Beyer, H.G.; Degner, T.; Gabler, H. "Operational Behavior of Wind/diesel Systems Incorporating Short-Term Storage: An Analysis via Simulation Calculations." Solar Energy, Vol. 54, No 6, pp. 429-439, 1995.

[12] Shirazi, M.; Drouilhet, S. (1997). "An Analysis of the Performance Benefits of Short-Term Energy Storage in Wind/diesel Hybrid Power Systems.” 1997 ASME Wind Energy Symposium, Reno, Nevada, January 6-9, 1997.

[13] Drouilhet, S.; Shirazi, M. (2002). Wales, Alaska High-Penetration Wind/diesel Hybrid Power System: Theory of Operation. 77 pp.; NREL Report No. TP-500-31755.

[14] Australian Greenhouse Office, renewable energy enabling technologies, King Island Project http://www.greenhouse.gov.au/renewable/recp/enabling/three.html and http://www.greenhouse.gov.au/renewable/recp/enabling/four.html

[15] VRB Power Systems Incorporated, King Island case study www.vrbpower.com/publications/casestudies.html

[16] Hamsic, N.; Schmelte, A.; Mohd, A.;Ortjohann, E.; Schultze, E.; Tuckey, A.; Zimmermann, J. "Increasing Renewable Energy Penetration in Isolated Grids Using a Flywheel Energy Storage System." 2007, International Conference on Power Engineering, Energy and Electrical Drives (POWERENG), Portugal, April 2007.

[17] Norway's Utsira Island Launches Energy Independence via Wind, H2 Power" The Hydrogen \& Fuel Cell Letter, August 2004, Vol. XIX, No8. http://www.hfcletter.com/pub/XIX 8/stories/169-1.html

[18] Alaska Energy Authority (2007), Statistical Report of the Power Cost Equalization Program, Fiscal year 2006. http://www.aidea.org/aea/PDF\%20files/2007PCEStatisticsFY06.pdf

[19] Conover, K.; VandenBosche, J.; Rhoads, H.; Smith, B. (2000). Review of Operation and Maintenance Experience in the DOE-EPRI Wind Turbine Verification Program. 13 pp.; NREL Report No. CP-500-28620.

[20] Drouilhet, S. (2001). Preparing an Existing Diesel Power Plant for a Wind Hybrid Retrofit: Lessons Learned in the Wales, Alaska, Wind/Diesel Hybrid Power Project. 13 pp.; NREL Report No. CP500-30586.

[21] Web site for Wind Powering America, Wind/Diesel 2002 Workshop Proceedings, http://www.eere.energy.gov/windpoweringamerica/wkshp_2002_wind_diesel_4.html.

[22] Laakso. T.; Holttinen, H.; Ronsten, G.; Tallhaug, L.; Horbaty, R.; Baring-Gould, I.; Lacroix, A.; Peltola, E.; Tammelin, B. "State-of-the-art of wind energy in cold climates." IEA, Task 19 Technical Report, 2003. http://arcticwind.vtt.fi/reports/state_of the art.pdf

[23] Laakso, T.; Tallhaug, L.; Ronsten, G.; Horbaty, R.; Baring-Gould, I.; Lacroix, A.; Peltola, E. "Expert Group Study on Wind Energy Projects in Cold Climates." IEA, Task 19 Technical Report, 2005. http://virtual.vtt.fi/virtual/arcticwind/reports/recommendations.pdf

[24] Rhoads, H.; VandenBosche, J.; McCoy, T.; Compton, A.; Smith, B. (2000). Comparison of Projections to Actual Performance in the DOE-EPRI Wind Turbine Verification Program. 14 pp.; NREL Report No. CP-500-28608.

[25] Devine, M.; Loewen, R.; Flowers, L. (2006). Wind Energy in Alaska: Progress, Barriers, and the Path Forward. Proceedings of the 2006 AWEA Conference, Pittsburgh, PA. June 2006. 


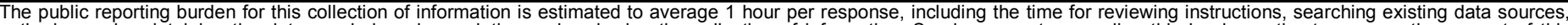

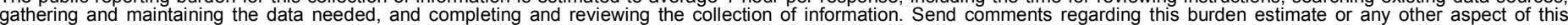

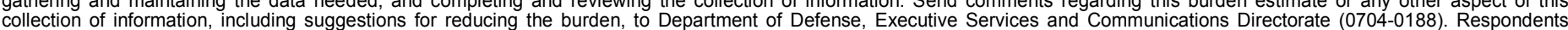

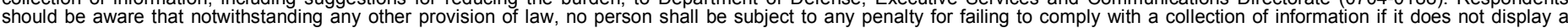

should be awa e that notwithstanding

PLEASE DO NOT RETURN YOUR FORM TO THE ABOVE ORGANIZATION.

\begin{tabular}{l|l|l|l} 
1. REPORT DATE $(D D-M M-Y Y Y Y)$ & 2. & REPORT TYPE & 3. DATES COVERED (FrOm - TO)
\end{tabular}

December 2007

Conference Paper

4. TITLE AND SUBTITLE
Status of Wind-Diesel Applications in Arctic Climates: Preprint

5a. CONTRACT NUMBER

DE-AC36-99-GO10337

5b. GRANT NUMBER

5c. PROGRAM ELEMENT NUMBER

6. AUTHOR(S)

I. Baring-Gould and D. Corbus

5d. PROJECT NUMBER

NREL/CP-500-42401

5e. TASK NUMBER

WER69001

5f. WORK UNIT NUMBER

7. PERFORMING ORGANIZATION NAME(S) AND ADDRESS(ES)

National Renewable Energy Laboratory

8. PERFORMING ORGANIZATION REPORT NUMBER

1617 Cole Blvd.

NREL/CP-500-42401

Golden, CO 80401-3393

9. SPONSORING/MONITORING AGENCY NAME(S) AND ADDRESS(ES)

10. SPONSOR/MONITOR'S ACRONYM(S) NREL

11. SPONSORING/MONITORING AGENCY REPORT NUMBER

12. DISTRIBUTION AVAILABILITY STATEMENT

National Technical Information Service

U.S. Department of Commerce

5285 Port Royal Road

Springfield, VA 22161

13. SUPPLEMENTARY NOTES

14. ABSTRACT (Maximum 200 Words)

The rising cost of diesel fuel and the environmental regulation for its transportation, use, and storage, combined with the clear impacts of increased arctic temperatures, is driving remote communities to examine alternative methods of providing power. Over the past few years, wind energy has been increasingly used to reduce diesel fuel consumption, providing economic, environmental, and security benefits to the energy supply of communities from Alaska to Antarctica. This summary paper describes the current state of wind-diesel systems, reviews the operation of wind-diesel plants in cold climates, discusses current research activities pertaining to these systems, and addresses their technical and commercial challenges. System architectures, dispatch strategies, and operating experience from a variety of wind-diesel systems in Alaska will be reviewed. Specific focus will also be given to the control of power systems with large amounts of wind generation and the complexities of replacing diesel engine waste heat with excess wind energy, a key factor in assessing power plants for retrofit. A brief overview of steps for assessing the viability of retrofitting diesel power systems with wind technologies will also be provided. Because of the large number of isolated diesel minigrids, the market for adding wind to these systems is substantial, specifically in arctic climates and on islands that rely on diesel-only power generation.

15. SUBJECT TERMS

wind energy; wind-diesel system; hybrid system; energy; Arctic; Alaska; Wales; Kotzebue

\begin{tabular}{|c|c|c|c|c|}
\hline \multicolumn{3}{|c|}{ 16. SECURITY CLASSIFICATION OF: } & \multirow{2}{*}{$\begin{array}{l}\text { 17. LIMITATION } \\
\text { OF ABSTRACT } \\
\text { UL }\end{array}$} & \multirow{2}{*}{$\begin{array}{l}\text { 18. NUMBER } \\
\text { OF PAGES }\end{array}$} \\
\hline $\begin{array}{l}\text { a. REPORT } \\
\text { Unclassified }\end{array}$ & $\begin{array}{l}\text { b. ABSTRACT } \\
\text { Unclassified }\end{array}$ & $\begin{array}{l}\text { c. THIS PAGE } \\
\text { Unclassified }\end{array}$ & & \\
\hline
\end{tabular}
19a. NAME OF RESPONSIBLE PERSON

19b. TELEPHONE NUMBER (Include area code) 